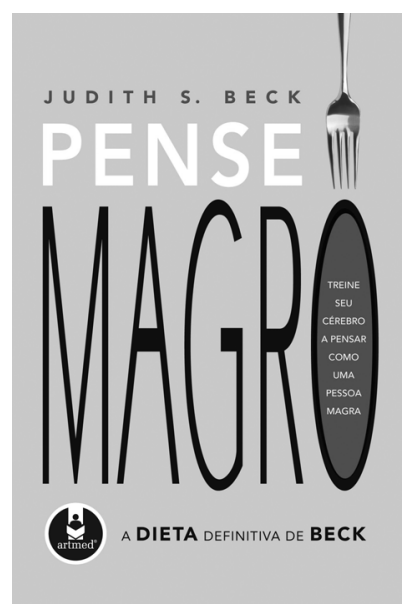

\title{
Pense magro: treine seu cérebro a pensar como uma pessoa magra A dieta definitiva de Beck
}

\author{
Judith Beck
}

Porto Alegre, Artmed, 2008

\section{Melanie Ogliari Pereira*}

* Psiquiatra, Terapeuta cognitiva, Beck Institute for Cognitive Therapy and Research, Bala Cynwyd, PA, EUA. Membro fundador, Academy of Cognitive Therapy, Philadelphia, PA, EUA.

Lançado no segundo semestre de 2007 nos EUA, o livro da Dra. Judith Beck foi traduzido e lançado pela Editora Artmed em agosto deste ano, 2008, na Bienal de São Paulo, sendo considerado um best-seller tanto no seu país de origem como no seu lançamento no Brasil.

O prefácio do Dr. Aaron Beck apresenta esse novo livro da Dra. Judith Beck como "um novo campo para a terapia cognitiva" e é definido pela autora como "uma opção para a problemática tarefa de emagrecer".

Direcionado para pacientes com obesidade, mas que da mesma forma que $A$ mente vencendo o humor, de Christine Padesky, poderá vir a ser utilizado por profissionais da saúde para abordagem desses indivíduos, o livro divide-se em suas 317 páginas em três segmentos: "O poder da terapia cognitiva para emagrecer"; "O programa"; "A continuidade".

$\mathrm{Na}$ introdução, a autora apresenta ao paciente a proposta de uma jornada em conjunto, com o objetivo de possibilitar ao indivíduo reconhecer seu padrão alimentar, suas distorções cognitivas relacionadas à perda de peso e ao seu corpo e como o modelo de reestruturação da terapia cognitiva poderá ajudá-lo a emagrecer e se manter magro.

A forma utilizada pela autora para escrever estabelece um tom de intimidade e cumplicidade entre o paciente e o terapeuta, característico desse tipo de abordagem e proposta.

O primeiro segmento, "O poder da terapia cognitiva", divide-se em quatro capítulos: "A chave do sucesso", "O que, na verdade, faz você comer", "Como as pessoas magras pensam", "Como utilizar a dieta definitiva de Beck".

No primeiro capítulo do segmento, "A chave do sucesso", Dra. Judith apresenta o modelo cognitivo para o paciente: "Sua maneira de pensar sobre alimentos, comer e fazer dieta influencia seu comportamento e como você se sente emocionalmente".

No segundo capítulo, "O que, na verdade, faz você comer", são abordados os conceitos e exemplos do que são pensamentos automáticos disfuncionais, que neste livro são denominados "pensamentos sabotadores", e que o ato de comer não é um 
comportamento automático, mas decorrente de estímulos.

A autora apresenta ao paciente que: "se você puder identificar estímulos que provocam pensamentos sabotadores e que o levam a comer de maneira inadequada, você poderá minimizar sua exposição a eles e mudar a forma de enfrentá-los".

No capítulo três, "Como as pessoas magras pensam", discorre sobre como pessoas magras conseguem distinguir entre fome e vontade de comer e como conseguem se programar e limitar sua alimentação de forma organizada e saudável.

São apresentadas características que diferenciam o magro da pessoa com obesidade, como, por exemplo, a baixa tolerância que o obeso tem à fome e ao desejo incontrolável de comer (que na linguagem coloquial do livro é a maneira como compulsão é denominada), sendo utilizadas vinhetas clínicas.

No capítulo quatro, "Como utilizar a dieta definitiva de Beck", o programa de 6 semanas é descrito de uma forma geral.

Portanto, o primeiro segmento do livro tem um papel mais psicoeducativo sobre obesidade e sobre como o modelo cognitivo poderá auxiliar como forma de intervenção e motivação desse transtorno.

No segundo segmento do livro - o programa -, a autora apresenta de forma detalhada semana a semana, dia a dia de cada semana, o processo do tratamento em si.

Cada semana do programa é apresentada com os objetivos a que se propõe da página 63 até a página 294. As semanas são apresentadas individualmente:

- Semana 1 - Prepare-se: aprenda os fundamentos;

- Semana 2 - Organize-se: prepare-se para fazer a dieta;

- Semana 3 - Vá em frente, comece a dieta;

- Semana 4 - Reaja aos pensamentos sabotadores;

- Semana 5 - Supere desafios;

- Semana 6 - Aprimore novas habilidades.

Neste segmento, "O programa", que é a maior parte do livro, a autora descreve com exemplos práticos como o paciente pode se preparar para poder fazer e manter sua dieta, ressaltando a importância da escolha de um esquema de dieta saudável e de ter um profissional que seja responsável por esse processo nutricionista, clínico, endócrino, etc.

Em cada dia, são apresentados exercícios práticos, como preenchimento de quadros de vantagens e desvantagens de emagrecer, cartões do tipo "razões pelas quais quero emagrecer", proposta de lista de tarefas para cada dia e a técnica das sete perguntas, que é como no livro o Registro de Pensamento Disfuncional é chamado.

Para cada dia, existe uma tarefa, uma habilidade a ser adicionada ao "arsenal" do paciente. Existem espaços para o paciente preencher no próprio livro. $\mathrm{O}$ programa tem ao todo 42 dias e coloca todo o instrumental da terapia cognitiva a serviço de ensinar o paciente a emagrecer e manter seu peso.

O segundo segmento do livro é onde o paciente aprende a ser seu próprio terapeuta para a tarefa de emagrecer e manter seu peso.

O último segmento, "A continuidade", é dedicado a ensinar estratégias cognitivas e comportamentais de manutenção, sendo composto por dois capítulos: "1. Quando parar de emagrecer"; e "2. Como manter seu novo peso".

Neste último segmento, o paciente aprende técnicas de prevenção de recaída e a elaborar um resumo do que lhe pareceu mais útil no processo de tratamento e que ele poderá utilizar pelo resto de sua vida.

Esse novo livro da Dra. Judith Beck direcionado para o público em geral, mas que certamente será também utilizado por profissionais de saúde, é uma proposta de abordagem para pacientes com obesidade emagrecerem de forma saudável, adequada e poderem manter essa perda de peso - razão pela qual qualifica a abordagem como "definitiva".

É um livro elegante, de fácil leitura, por sua linguagem coloquial, mas nem por isso uma proposta reducionista.

É mais uma ferramenta para o tratamento de pacientes com obesidade. Não é indicado para pacientes com transtornos alimentares. 